\title{
Histopathological Study of Tumor and Tumor Like Lesions of The Oral Cavity
}

\author{
Babai Halder and Nirvana Rasaily Halder*
}

Assistant Professor, Department of Pathology, Mamata Medical College, Rotary Nagar, Khammam-507002. Telangana. India

\begin{abstract}
Background: The oral cavity is one of the most common site for various tumor and tumor like lesions. Development of oral cavity lesions are strongly linked with smoking. Hemangioma is the commonest benign tumor. Inflammatory fibrous hyperplasia is the commonest nonneoplastic reactive lesion. Squamous cell carcinoma (SCC) is most common among malignant lesions.
\end{abstract}

Aims \& Objectives: To study the histopathological patterns \& variations of oral cavity lesions.

Materials and Methods: A three year retrospective cross-sectional study by histopathological examination.

Results: A total of 105 cases were subjected to histopathological examination. Among these, 28 cases (26.66\%) were benign, 27 cases $(25.71 \%)$ were malignant and 4 cases $(3.80 \%)$ were pre-malignant lesions. Among the malignant lesions, SCC was most common ( $85.19 \%)$, while inflammatory fibrous hyperplasiawas most common among non- neoplastic lesions ( $45.65 \%)$. Overall females were affected more than males (M: $\mathrm{F}=1: 1.1)$, though malignant lesions were more common in males. Malignant lesions were more common in older age group (mean age 52.26\%), while non-neoplastic lesions were common in younger age group (mean age 37.87\%). Malignant lesions were most common intongue (11 cases, $40.74 \%$ ), while benign lesions were most common in gingiva (10cases, 35.71\% ).

Conclusion: A variety of benign and malignant tumors occur in oral cavity. However, the origin and nature of the oral cavity lesions cannot be confirmed by clinical examination alone. Hence, histopathological examination is essential to confirm the diagnosis and malignant potential of the oral cavity lesions.

Keywords: Oral Cavity, Benign Lesion, Malignant Lesion, Squamous Cell Carcinoma

\section{Introduction}

The oral cavity includes the lips, the hard palate, the upper and lower alveolar ridge, the anterior two thirds of the tongue, sublingual region, the buccal mucosa, the retromolar trigone and the floor of the mouth (mylohyoid, digastric, geniohyoid muscles). ${ }^{[1]}$ The oral cavity is the first part of digestive system and there are many types of tissues like bone of mandible and maxilla, epithelial tissue of oral mucosa, minor salivary glands, and odontogenic tissue; it is liable for different types of epithelial, mesenchymal and lymphoid tumors. ${ }^{[2]}$ It is directly exposed to tobacco, alcohol, and food. ${ }^{[3]}$ It is one of the most common sites for various tumors and tumor like lesions. ${ }^{[4]}$ Tumor may originate from epithelial tissue, connective tissue, muscle tissue, nerve tissue and from vessels. ${ }^{[5]}$

The most common oral lesions are candidiasis, recurrent herpes, recurrent aphthous stomatitis, mucocele, fibroma, pyogenic granuloma, hairy tongue, lichen planus, and leukoplakia which were confirmed by the large-scale, population based screening studies..$^{[2,6]}$ These lesions have been diagnosed clinically without biopsy.

Other common lesions that are seen in routine work are those lesions which have arisen from the mandible, include both odontogenic and nonodontogenic origins and have varying degrees of destructive potential, as well as common benign cystic lesions which include periapical (radicular) cysts, follicular (dentigerous) cysts, and odontogenic keratocysts. $^{[7,8]}$

In addition, vascular tumors such as hemangioma and arteriovenous malformations are frequently seen in this site of the body. The benign tumors that have arisen from odontogenic structures and from mandible and maxilla include several types like cementoma, ossifying fibroma, Odontogenic myxoma, periapical cemental dysplasia. While the borderline and malignant tumors are ameloblastoma, ameloblastic carcinoma, ameloblastic fibrosarcoma, osteosarcoma, and metastatic tumors. ${ }^{[9,10]}$

In the developing world oral cancer is the third most common cancer after stomach and cervical cancer. An estimated 378,500 new cases of intra-oral cancer are diagnosed annually worldwide. ${ }^{[1]}$ The oral cavity is more accessible to complete examination; detection of precancerous and cancerous lesions can be done at earlier stage. Oral cancer has better prognosis and may be controlled effectively, if it is diagnosed at an early stage. ${ }^{[12]}$ Biopsy of lesion of oral cavity is an easy outpatient procedure and gives definitive diagnosis. 
The present study is undertaken with a view to study various tumor and tumor like lesions of the oral cavity and also to find out the prevalence rate of the various conditions.

\section{Materials and Methods}

Retrospective study was carried out in the Department of Pathology, Mamata Medical College \& Hospital, Khammam.

Patient's age, sex, clinical data, site of lesions, and type of operation were retrieved from the request forms manually. Biopsies were examined grossly concerning the size and shape of material. The surgical specimens were immediately fixed in $10 \%$ formaldehyde, and then the biopsies were routinely processed. One cassette was taken, then the material was embedded in paraffin, and sections were stained with hematoxylin and eosin ( $\mathrm{H} \&$ E) stains. Microscopical interpretation was then done. The lesions were divided into four major categories such as non-neoplastic, benign, precursor/pre-malignant and malignant. Finally, the results were analyzed accordingly.

\section{Results}

A total of 105 cases were subjected to histopathological examination. Out of these, 46 were non-neoplastic reactive lesions $(43.80 \%), 28$ were benign tumors $(26.66 \%), 4$ precursor/ pre-malignant lesions $(3.80 \%)$ and 27 were malignant (25.71\%). In our study affected age ranging from 11 to 75 years with mean age of 40.5 years. Overall females were affected more than males (1.1: 1), though malignant lesions were more common in males (1.7: 1). Malignant lesions were more common in older age group (mean age $52.26 \%$ ) while non-neoplastic lesions were common in younger age group (mean age $37.87 \%$ ). Malignant lesions were most common in tongue (11 cases, $40.74 \%$ ), while benign lesions were most common in gingiva (10 cases, $35.71 \%$ ).

Majority of malignant lesions were well differentiated SCC (85.19\%). Among the non-neoplastic lesions, inflammatory fibrous hyperplasia was the commonest lesion (45.65\%). Among benign tumors hemangioma was the commonest. Among the premalignant lesions, leukoplakia was common. Our study showed non-neoplastic lesions far outnumber tumors.

\section{Discussion}

Oral cavity tumor and tumor like lesions are commonly encountered in practice. This study includes a total of 105 oral cavity lesions, including non-neoplastic inflammatory lesions, benign, premalignant and malignant lesions. The

Table 1: Overall distribution of oral cavity lesions.

\begin{tabular}{|c|c|c|}
\hline SI. No. & Type of lesions $(\mathbf{n = 1 0 5 )}$ & No. $(\mathbf{\%})$ \\
\hline $\mathbf{1 .}$ & Non-neoplastic $(\mathbf{n = 4 6})$ & $\mathbf{4 6}(\mathbf{4 3 . 8 1 \% )}$ \\
\hline a) & Inflammatory fibrous hyperplasia & $21(45.65 \%)$ \\
\hline b) & Mucocoele & $15(32.61 \%)$ \\
\hline c) & Fibroma & $07(15.22 \%)$ \\
\hline d) & Inflammatory granulation tissue & $03(6.52 \%)$ \\
\hline $\mathbf{2}$. & Benign (n=28) & $\mathbf{2 8 ( 2 6 . 6 7 \% )}$ \\
\hline a) & Hemangioma & $14(50 \%)$ \\
\hline b) & Squamous pappiloma & $08(28.57 \%)$ \\
\hline c) & Pyogenic granuloma & $06(21.43 \%)$ \\
\hline $\mathbf{3 .}$ & Precursor /pre-malignant (n=4) & $\mathbf{0 4}(\mathbf{3 . 8 1 \% )}$ \\
\hline a) & Leukoplakia & $04(100 \%)$ \\
\hline $\mathbf{4 .}$ & Malignant (n=27) & $\mathbf{2 7}(\mathbf{2 5 . 7 1 \% )}$ \\
\hline a) & SCC & $23(85.19 \%)$ \\
\hline b) & Basal cell carcinoma (BCC) & $3(11.11 \%)$ \\
\hline c) & Malignant fibrous histiocytoma (MFH) & $1(3.70 \%)$ \\
\hline
\end{tabular}

Table 2: Sex wise distribution of oral cavity lesions.

\begin{tabular}{|c|c|c|c|}
\hline SI. No. & Type of lesions & Male (\%) & Female \\
\hline 1. & Non-neoplastic $(\mathrm{n}=46)$ & $18(39.13 \%)$ & $28(60.87 \%)$ \\
\hline 2. & Benign $(\mathrm{n}=28)$ & $13(46.43 \%)$ & $15(53.57 \%)$ \\
\hline 3. & Precursor/Premalignant $(\mathrm{n}=4)$ & $2(50 \%)$ & $2(50 \%)$ \\
\hline 4. & Malignant $(\mathrm{n}=27)$ & $17(62.96 \%)$ & $10(37.04 \%)$ \\
\hline Total $(\mathrm{n})=\mathbf{1 0 5}$ & & $\mathbf{5 0}(\mathbf{4 7 . 6 2} \%)$ & $\mathbf{5 5}(\mathbf{5 2 . 3 8 \% )}$ \\
\hline
\end{tabular}


Table 3: Age wise distribution of oral cavity lesions.

\begin{tabular}{|c|c|c|c|c|c|}
\hline SI. No. & Age groups & $\begin{array}{c}\text { Non-neoplastic } \\
\qquad(n=46)\end{array}$ & $\begin{array}{l}\text { Benign } \\
(n=28)\end{array}$ & $\begin{array}{l}\text { Precursor } \\
(n=4)\end{array}$ & $\begin{array}{l}\text { Malignant } \\
\quad(n=27)\end{array}$ \\
\hline 1. & $11-20$ & $2(4.35 \%)$ & $1(3.57 \%)$ & - & - \\
\hline 2. & $21-30$ & $16(34.78 \%)$ & $9(32.14 \%)$ & - & - \\
\hline 3. & $31-40$ & $24(52.17 \%)$ & $12(42.86 \%)$ & - & $1(3.70 \%)$ \\
\hline 4. & $41-50$ & $3(6.53 \%)$ & $4(14.29 \%)$ & $1(25 \%)$ & $7(25.93 \%)$ \\
\hline 5. & $51-60$ & $1(2.17 \%)$ & $1(3.57 \%)$ & $2(50 \%)$ & $14(51.85 \%)$ \\
\hline 6. & $61-70$ & - & $1(3.57 \%)$ & $1(25 \%)$ & $3(11.11 \%)$ \\
\hline 7. & $>70$ & - & - & - & $2(7.41 \%)$ \\
\hline
\end{tabular}

Table 4: Site wise distribution of oral cavity lesions.

\begin{tabular}{|c|c|c|c|c|c|c|}
\hline SI. No. & Site & $\begin{array}{c}\text { Non-neoplastic } \\
(\mathbf{n = 4 6 )}\end{array}$ & Benign $(\mathbf{n = 2 8 )}$ & Precursor $(\mathbf{n = 4 )}$ & $\begin{array}{c}\text { Malignant } \\
(\mathbf{n}=\mathbf{2 7})\end{array}$ & Total $(\mathbf{n = 1 0 5 )}$ \\
\hline 1. & Tongue & $19(41.31 \%)$ & $6(21.43 \%)$ & - & $11(40.74 \%)$ & $36(34.28 \%)$ \\
\hline 2. & Lips & $4(8.70 \%)$ & $8(28.57 \%)$ & - & $6(22.22 \%)$ & $18(17.14 \%)$ \\
\hline 3. & Gingiva & $1(2.17 \%)$ & $10(35.71 \%)$ & $1(25 \%)$ & $5(18.52 \%)$ & $17(16.19 \%)$ \\
\hline 4. & Buccal mucosa & $10(21.74 \%)$ & $1(3.57 \%)$ & $1(25 \%)$ & $3(11.11 \%)$ & $15(14.29 \%)$ \\
\hline 5. & Palate & $6(13.04 \%)$ & - & $2(50 \%)$ & - & $8(7.62 \%)$ \\
\hline 6. & Others & $6(13.04 \%)$ & $3(10.72 \%)$ & - & $2(7.41 \%)$ & $11(10.48 \%)$ \\
\hline
\end{tabular}

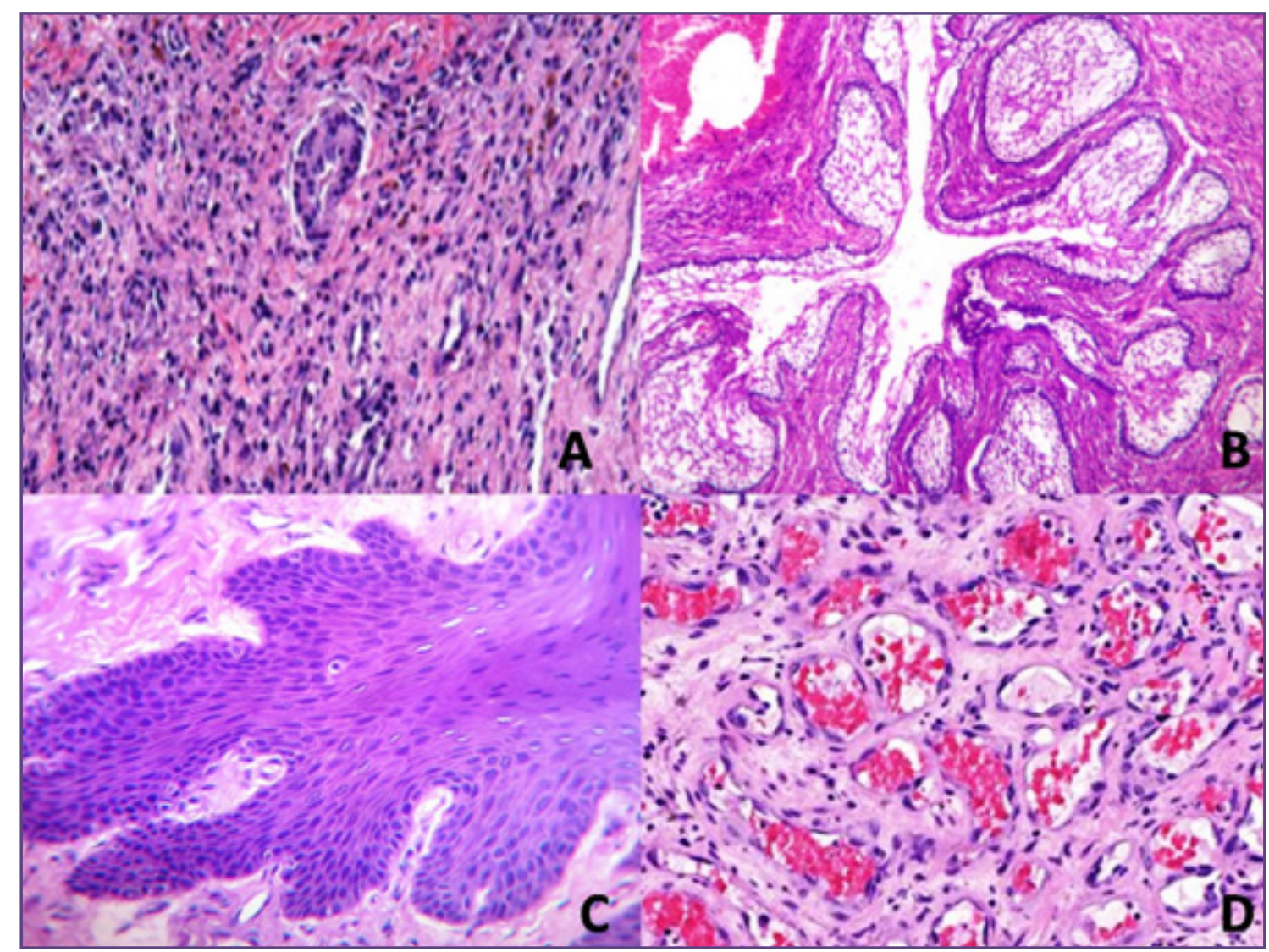

Fig. 1: A. Inflammatory fibrous hyperplasia-submucosal fibroushyperplasia with chronic inflammatory infiltrates; B. Mucocoele-retention mucocoele showing mucous filled cysts lined by cuboidal epithelium;C. Squamous papilloma-papillary fronds with central fibrovascular core and mature hyperplastic squamous epithelium; D. Hemangioma-proliferation of endothelial lined vascular channels with red blood cells and surrounding scant fibrous stroma (H \& E Stain, 10x). 


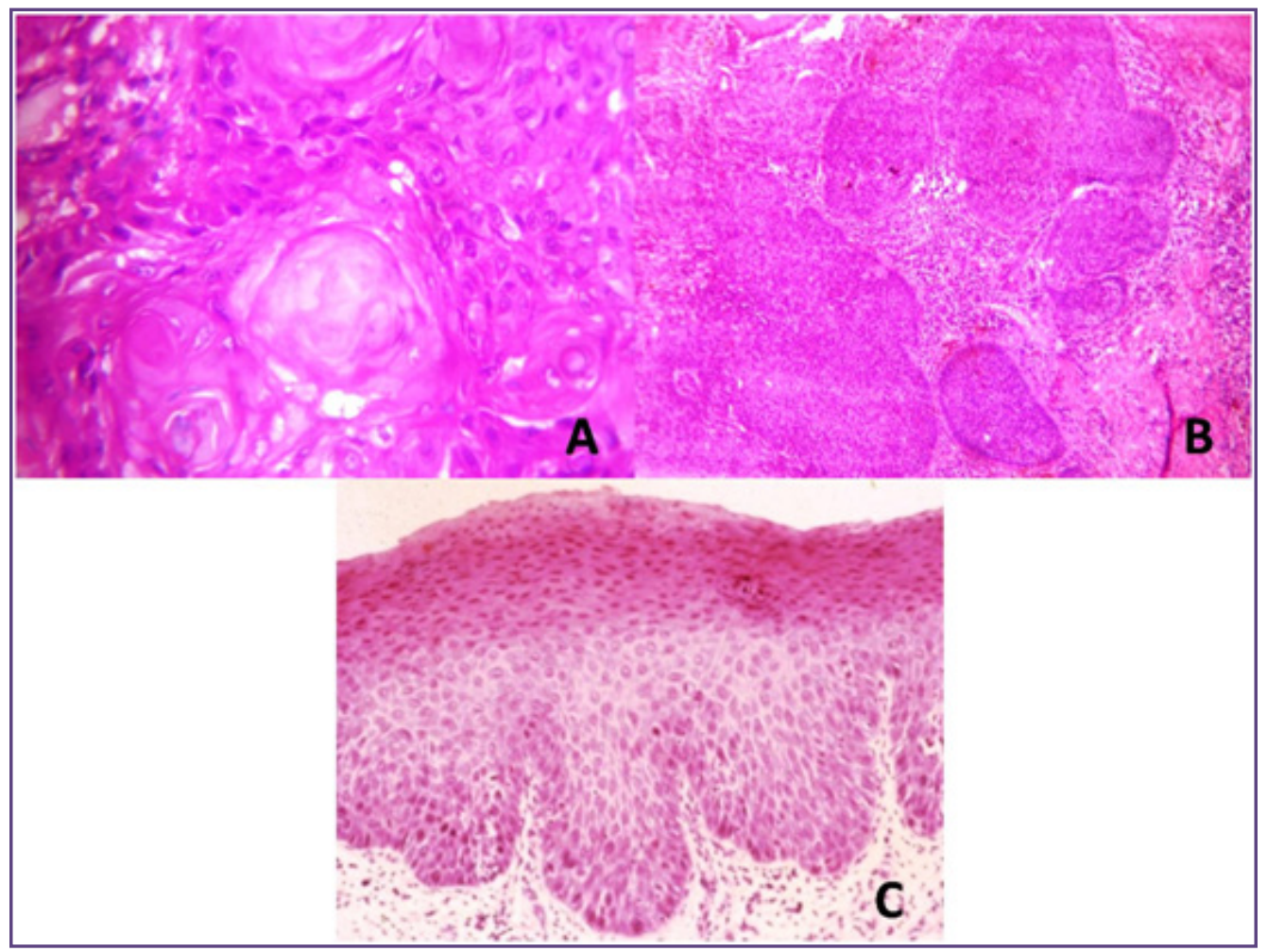

Fig. 2: A. Well differentiated SCC-cells with polygonal outlines,prominent intercellular bridges, horn pearls and stromal invasion; B. Basal cell carcinoma-nests and islands of basaloid cells, peripheral palisading, myxoid stroma and retraction clefting; C. Leukoplakia- acanthosis with low grade dysplasia and stromal inflammatory infiltrates(H \& E Stain, 10x).

cases were studied in order to know the histopathological patterns and exclude malignancy.

In our study, the affected age range was 11 to 75 years with a mean age of 40.5 years and male: female (M:F) ratio was $1: 1.1$, though malignant lesions were more common in males (M:F ratio 1.5:1). Similar findings were noted by Kashyap B et al, ${ }^{[13]}$ in which out of 100 cases studied, mean age was 36 years and M:F ratio was 1:2. While, Fang QG et $a l^{[14]}$ found in their study that the mean age of the patients was 65 years. Out of the 24 malignant lesions, there was found to be a male preponderance comprising 14 cases (58.33\%), and females comprised 10 cases (41.66\%).

Present study showed most common site for oral cavity lesions was the tongue (34.28\%) followed by the lips (17.14\%), gingiva (16.19\%) and buccal mucosa (14.29\%). Similar findings were noted by Mehta NV et al, ${ }^{[15]}$ where the most common site was found to be the buccal mucosa followed by the lips. These findings are comparable with a study done by Dhanuthai $\mathrm{K}$ et al, ${ }^{[16]}$ where most cases of oral cancer were encountered in the tongue. While in a study done by Shah PY et al ${ }^{[17]}$ revealed that the oral mucosa was the most common site for oral cancer followed by the tongue.
In our study, $41.66 \%$ of the patients with oral SCC had history of tobacco use, $29.1 \%$ had history of alcoholism and $70.83 \%$ had the habit of taking betel quid. These findings are similar to those observed by Fang QG et al, ${ }^{[14]}$ in which $61.3 \%$ patients had history of tobacco use and $38.8 \%$ had history of alcoholism. In a study done by Kumar M et al, ${ }^{[18]}$ the most common risk factor for oral cancer was tobacco smoking and betel quid chewing.

Present study revealed most of the oral cavity SCC were well differentiated SCC. In a study by Fang QG et al, ${ }^{[14]}$ $53.73 \%$ of all SCC were well differentiated, $34.32 \%$ were moderately differentiated and $11.94 \%$ were poorly differentiated. Halboub ES et al ${ }^{[19]}$ found similar results in their study where most of the oral cancers were well differentiated and moderately differentiated SCC.

Hemangioma was to be the most common benign tumor in the oral cavity in present study, followed by squamous papilloma. According to study done by Allon I et al, ${ }^{[20]}$ lipomatous tumors and hemangioma were the most frequent benign oral cavity tumors.

In our study leukoplakia was found to be the most common pre-malignant lesion which is in accordance to a study done by Jagtap SV et al. ${ }^{[1]}$ 


\section{Conclusion}

Oral cavity tumor and tumor like lesions are frequently encountered. Early recognition of potentially malignant lesions and insight into the risk factors are important. SCC is the most common malignant tumor in oral cavity. Histopathological examination is a valuable tool for diagnosis of the oral cavity lesions and providing proper treatment.

\section{References}

1. Vogel DWT, Zbaeren P, Thoeny HC. Cancer of the Oral cavity and Oropharynx. Cancer Imaging 2010;10:62-72.

2. Schulman JD, Beach MM, Rivera-Hidalgo F. The prevalence of oral mucosal lesions in U.S. adults: data from the Third National Health and Nutrition Examination Survey, 19881994. J Am Dent Assoc 2004; 135:1279-86.

3. Mark W. Lingen and Vinay Kumar. Head \& Neck (Oral Cavity), A Text Book of Robins and Cotran. Pathologic Basis of Disease. 7th ed. India: Elsevier; 2004. p.774-82.

4. Nikunj V.M, Kalpana K. Dave, R.N. Gonsai et al. Histopathological study of oral cavity lesions: A study of 100 cases. Int J Cur ResRev 2013;5(10):110-6.

5. Shafer. Benign and Malignant Tumors of Oral Cavity, A Text book of oral pathology, 4th edn. Harcourt Indian Pvt. Ltd. W.B. Saunder's Co., 1993. p. 86-215.

6. Bouquot JE. Common oral lesions found during a mass screening examination. J Am Dent Assoc 1986;112:50-7.

7. PN Ramachandrau Naiv, Giou Pajarola. Types and incidence of human periapical lesions obtained with extracted teeth. Oral Surg Oral Med Oral Path Oral Radio Endod 1996;81:93102.

8. Adelberto Mosquedo, Taylor Coustantino Ledeswa, Montes Silivia Caballero, et al. Odontogenic tumors in Mexico A collaborative retrospective study of 349 cases. Oral Surg Oral Med Oral Path Oral Radio Endod.1997;84:672-5.

9. Kramer IRH, Pindborg JJ, Shar M. Histological typing of odontogenic tumors. World Health Organization- international histological classification of tumors. 2nd ed. Berlin, Germany: Springer-Verlag; 1992.p.1-42.

10. Weber AL, Bui C, Kaneda T. Malignant tumors of the mandible and maxilla. Neuroimaging Clin $\mathrm{N}$ Am 2003;13(3):509-24.

11. Ayaz B, Saleem K, Azim W, Shaikh A. A clinincopathological study of oral cancers. Biomedica 2011;27:29-32.

12. Singh AD. Challenge of Oral Cancer in India. Indian J Radiol 1981;35(3):147-55.

13. Kashyap P, Sridhar P, Nalini P. Reactive lesions of the oral cavity: Contemp Clin Dent 2012;3(3):294.

14. Fang QG, Shuang S, Zhen NL, Zhang X, Liua FY, Zhong $F$ et al. Squamous cell carcinoma of the buccal mucosa: Analysis of clinical presentation, outcome and prognostic factors. Mol Clin Oncol 2013;1:531-4.

15. Mehta NV, Dave KK, Gonsai RN, Goswami HM, Patel PS, Kadam TB.Histopathological study of oral cavity lesions. IJCRR 2013;5(10):110-6.

16. Dhanuthai K, Rojanawatsirivej S, Thosaporn W, Kintarak S, Subarnbhesaj A, Darling M et al. Oral cancer: A multicenter study. Med Oral Patol Oral Cir Bucal. 2018;23(1):e23-9.

17. Shah PY, Patel RG, Prajapati SG. Histopathological study of malignant lesions of oral cavity. Int J Med Sci Public Health 2017;6(3):472-8.

18. Kumar M, Nanavati R, Modi TG, Dobariya C. Oral cancer: Etiology and risk factors: A review. J Can Res Ther 2016;12:458-63.

19. Halboub ES, Abdulhuq M, Al-Mandili A. Oral and pharyngeal cancers in Yemen:a retrospective study: EMHJ 2012;18(9):985-91.

20. Allon I, Kaplan I, Gal G, Chaushu G, Allon DM. The clinical characteris- . The clinical characteris The clinical characteristics of benign oral mucosal tumors. Med Oral Patol Oral Cir Bucal 2014;19(5):e438-43.

21. Jagtap SV, Warhate P, Saini N, Jagtap SS, Chougule PG. Oral premalignant lesions: a clinicopathological study. Int Surg J 2017;4:3477- 81.

*Corresponding author:

Dr. Nirvana Rasaily Halder, Assistant Professor, Department of Pathology, ,Mamata Medical College, Rotary Nagar,

Khammam, Telangana, India, Pin 507002.

Phone: +919573632216 .

Email: nirvana.rasaily@yahoo.com

Financial or other Competing Interests: None. 